\title{
Prevalence of cystic echinococcosis in Iran: a systematic review and meta-analysis
}

\author{
H.R. Khalkhali ${ }^{1}$, M. Foroutan ${ }^{2,3}$, S. Khademvatan ${ }^{4 *}$, \\ H. Majidiani ${ }^{2,3 *}$, S. Aryamand ${ }^{3}$, P. Khezri ${ }^{3}$ and A. Aminpour ${ }^{4}$ \\ ${ }^{1}$ Department of Biostatistics and Epidemiology, Inpatient's Safety Research \\ Center, Urmia University of Medical Sciences, Urmia, Iran: ${ }^{2}$ Department of \\ Parasitology, Faculty of Medical Sciences, Tarbiat Modares University, \\ Tehran, Iran: ${ }^{3}$ Student Research Committee, Urmia University of Medical \\ Sciences, Urmia, Iran: ${ }^{4}$ Cellular and Molecular Research Center \& \\ Department of Medical Parasitology and Mycology, Urmia University of \\ Medical Sciences, Urmia, Iran
}

(Received 17 January 2017; Accepted 3 May 2017; First published online 7 June 2017)

\begin{abstract}
As a significant zoonosis, cystic echinococcosis (CE) is endemic in some parts of the world, such as the Middle East. There are studies on the prevalence of this infection in animal and human reservoirs in Iran; hence, we conducted this metaanalysis to elucidate the prevalence of CE in Iran. English (PubMed, Scopus, Web of Science, Science Direct and Google Scholar) and Persian (Magiran, Iran Medex, Iran Doc and SID) databases were explored. In the case of definitive, animal and human intermediate hosts, 37, 90 and 33 studies, respectively, have been included in the current review from January 1990 to December 2015. According to outcomes of the heterogeneity test, either Der Simonian and Laird's random-effects method or Mantel-Haenszel's fixed-effects method were employed to pool the estimations. The pooled prevalence of Echinococcus granulosus infection in definitive hosts was calculated as $23.6 \%$ (95\% confidence interval $(\mathrm{CI})=17.6-30.1 \%)$. The weighted prevalence of animal and human hydatidosis was calculated as $15.6 \%(95 \% \mathrm{CI}=14.2-17.1 \%)$ and $4.2 \%(95 \% \mathrm{CI}=3.0-5.5 \%)$, respectively. Meanwhile, most cases of human hydatidosis were in southern Iran, with a prevalence of $5.8 \%(3.2-9.2 \%)$. In terms of human hydatidosis, more infections were found in rural regions, and mostly in female individuals. Egger's regression test revealed publication bias, with a remarkable impact on total prevalence of the infection in animal intermediate hosts $(P<0.001)$, while it was not significant in human hosts $(P=0.4)$ and definitive hosts $(P=0.3)$. According to the weighted estimated prevalence of cystic echinococcosis and its financial burden, implementing appropriate control programmes should be compulsory to decrease the burden of the disease in Iran.
\end{abstract}

*Fax: (+98 44) 3332036

E-mail: khademvatan@yahoo.com and hamidreza.majidiani@ gmail.com

\section{Introduction}

Zoonotic diseases are infections that are transmitted among vertebrate animal populations and human societies (Carmena \& Cardona, 2014). About one-fifth of zoonoses belong to parasitic infections (Torgerson \& Macpherson, 2011). Cystic echinococcosis (CE) is a zoonotic neglected 
tropical disease caused by larval stages (metacestodes) of Echinococcus granulosus, the smallest cestode of medical importance and the most common reason for contagion in production animals (Cardona \& Carmena, 2013). Echinococcosis is a cyclozoonosis that employs two vertebrate hosts to maintain its life cycle (Cardona \& Carmena, 2013; Khademvatan et al., 2013). It mostly occurs as a domestic cycle in cattle- and sheep-raising countries, although a sylvatic cycle among wild carnivore/wild herbivore populations also exists (Cardona \& Carmena, 2013; Carmena \& Cardona, 2014). Being in the small intestine of canids (definitive hosts), adult worms lay eggs or detach gravid proglottids, which are excreted with the faeces and contaminate the environment, such as grazing pastures; infection of domestic and wild ungulates (intermediate hosts) following ingestion of eggs would then occur by chance. In the intermediate hosts, metacestodes frequently migrate to the liver and lung parenchyma and develop into hydatid cysts (Cardona \& Carmena, 2013). Humans are considered to be dead-end intermediate hosts for unilocular echinococcosis. Disease consequences vary from asymptomatic to development of hydatid cysts in the liver, lung and any other parts of the body (McManus et al., 2003). The annual global occurrence of this parasitic complication ranges between 1 and 200 cases per 100,000 individuals (Pawłowski et al., 2001). Furthermore, in various medical centres of Iran, 1.18-3 cases per 100,000 persons have been identified during surgical operations (Fasihi Harandi et al., 2012). CE has been proved to be an important human and animal health concern in many rural regions of western and central Asia, China, Australia, North and East Africa, the Mediterranean territory and South America (Jenkins et al., 2005; Jenkins, 2006; Magambo et al., 2006; Moro \& Schantz, 2006a; Romig et al., 2006; Sadjjadi, 2006; Wang et al., 2008; Dakkak, 2010; McManus, 2010; Romig et al., 2011).

There is an inextricable link among human health, animal and environmental health. This association is wellrepresented by revitalization of infectious zoonoses such as $\mathrm{CE}$ in recent years, which accounts for a major worldwide burden. So, characterization of CE prevalence among animal species involved in the transmission cycle is of utmost medical and veterinary importance. Up to now, there have been many research papers on the prevalence of $\mathrm{CE}$ in animal hosts in Iran, but the lack of collective data on this subject has led us to design a systematic review and meta-analysis in the country.

\section{Methods \\ Study area}

Covering a wide area in the Middle East $\left(1,648,195 \mathrm{~km}^{2}\right)$, Iran is the 18th largest country worldwide, with a population of approximately 80 million in 2015 , located between $25^{\circ} 3^{\prime}$ and $39^{\circ} 47^{\prime} \mathrm{N}$, and $44^{\circ} 5^{\prime}$ and $63^{\circ} 18^{\prime} \mathrm{E}$, and bordering Iraq and Turkey in the west, Afghanistan and Pakistan in the east, the Persian Gulf and Oman Sea in the south, as well as Azerbaijan, Armenia and Turkmenistan in the north. Except for a small region on the margin of the Caspian Sea coast with a considerable annual rainfall and covered by dense vegetation, the general climate of Iran is hot and dry, forming the Iranian plateau. It is one of the world's most mountainous countries, its landscape dominated by rugged mountain ranges that separate various basins or plateaux from each other. The populous western part is the most mountainous, with ranges such as the Caucasus, Zagros and Alborz Mountains. Lower temperatures, severe winters and heavy snowfalls exist in the Zagros basin, while in the central and eastern basins there is an arid climate because of high-altitude mountain ranges in the western and northern parts. These mountain ranges are so high that rain clouds cannot reach the central and eastern basins. Annual precipitation is $680 \mathrm{~mm}$ in the eastern part of the plain and more than $1700 \mathrm{~mm}$ (66.9 inches) in the western part (https://en.wikipedia.org/wiki/Iran).

\section{Search strategy}

In order to appraise the prevalence of cystic echinococcosis in Iran, we conducted a systematic review depending on English and Persian online-released literature. The search procedure was performed in five English databases (PubMed, Scopus, Web of Science, Science Direct and Google Scholar) and four Persian databases (Magiran, Iran Medex, Iran Doc and Scientific Information Database) from January 1990 to December 2015 and the medical subject headings $(\mathrm{MeSH})$ terms used for this review were as follows: 'Echinococcus granulosus', 'Echinococcosis', 'Hydatid', 'Hydatic', 'Epidemiology', 'Prevalence' and 'Iran', alone or in combination.

\section{Study selection and data extraction}

In accordance with the inclusion criteria, cross-sectional studies on the prevalence of CE in definitive and/or intermediate hosts were included. Two autonomous reviewers carefully read and revisited all included papers. Also, incoherence among studies was obviated by discussion and consensus. A data extraction form was designed on the basis of the kind of animals, infected organs (in the case of intermediate hosts), number of studies and positive cases, as well as geographical region, and was used for the accurate information needed. Meanwhile, two risk factors were considered for cases of human echinococcosis, i.e. place of residence and gender. We performed a current meta-analysis according to PRISMA guidelines (Preferred Reporting Items for Systematic reviews and MetaAnalysis) (Moher et al., 2010).

\section{Meta-analysis}

The meta-analysis procedure was performed as described previously (Foroutan-Rad et al., 2016a, b; Foroutan et al., 2017; Khademvatan et al., 2017). Briefly, we estimated the prevalence and $95 \%$ confidence interval (CI) of animal echinococcosis for every study that was included. The findings of the meta-analysis were represented by a forest plot diagram, which shows estimates of prevalence and their respective CIs of individual studies with the summary measure. Cochran's $Q$ and $I^{2}$ statistics were used for evaluation of heterogeneity and inconsistency, respectively. In addition, small study effects and publication bias were calculated using funnel plot diagrams based on Egger's regression test. According to outcomes of the heterogeneity test, 
either Der Simonian and Laird's random-effects method or Mantel-Haenszel's fixed-effects method were employed to pool the estimations. Furthermore, studies were categorized in terms of geographical areas (north, east, west, south and centre) of Iran and total prevalence was appraised in five different regions.

\section{Results \\ Definitive hosts}

Based on the review of literature and within the frame of inclusion criteria, 37 out of 5363 records on the prevalence of $\mathrm{CE}$ in definitive hosts qualified for this systematic review and meta-analysis (fig. 1 and supplementary table S1).

Table 1 illustrates the findings obtained from the literature search as well as specifications of included studies. It shows the number of canids that were tested in terms of echinococcosis from 1990 until 2015 in various geographical foci of the country (table 1).

The calculated total prevalence of Echinococcus infection in definitive hosts was $23.6 \%$ (95\% CI $=17.6-30.1 \%)$. Most canids were found to be infected in the south of Iran, $36.2 \%(95 \% \mathrm{CI}=27.0-46.1 \%)$, but the fewest cases of infection were detected in the east, $15.3 \%(95 \% \mathrm{CI}=8.0-24.1 \%)$ (table 2). Publication bias was detected using Egger's regression test, but didn't have a significant impact on total prevalence estimates in definitive hosts $(P=0.31)$ (table 2).

Meta-regression results showed that there is a statistically significant correlation between total prevalence and both year of studies and sample size $(P=0.04$ for both) (figs 2 and 3).

\section{Animal intermediate hosts}

In total, 90 studies in the field of CE prevalence in animal intermediate hosts were gathered (fig. 1 and supplementary table S2). Database results, number of studies and positive cases are summarized in table 3.

The total prevalence of infection in animal intermediate hosts was assessed as $15.6 \%$ (95\% CI $=14.2-17.1 \%)$. In herbivores, the highest and lowest prevalence rates were observed in the north, 20.2\% (95\% CI = 13.7-27.7\%), and in central Iran, $11.0 \%(95 \% \mathrm{CI}=7.4-15.0 \%)$, respectively (table 4). Egger's regression test revealed statistically very significant publication bias $(P<0.001)$ (table 4$)$.

In compliance with the meta-regression, there was a remarkable relationship between weighted prevalence and sample size $(P=0.050)$, although prevalence didn't show any substantial correlation with year of studies $(P=0.29)$ (figs 4 and 5).
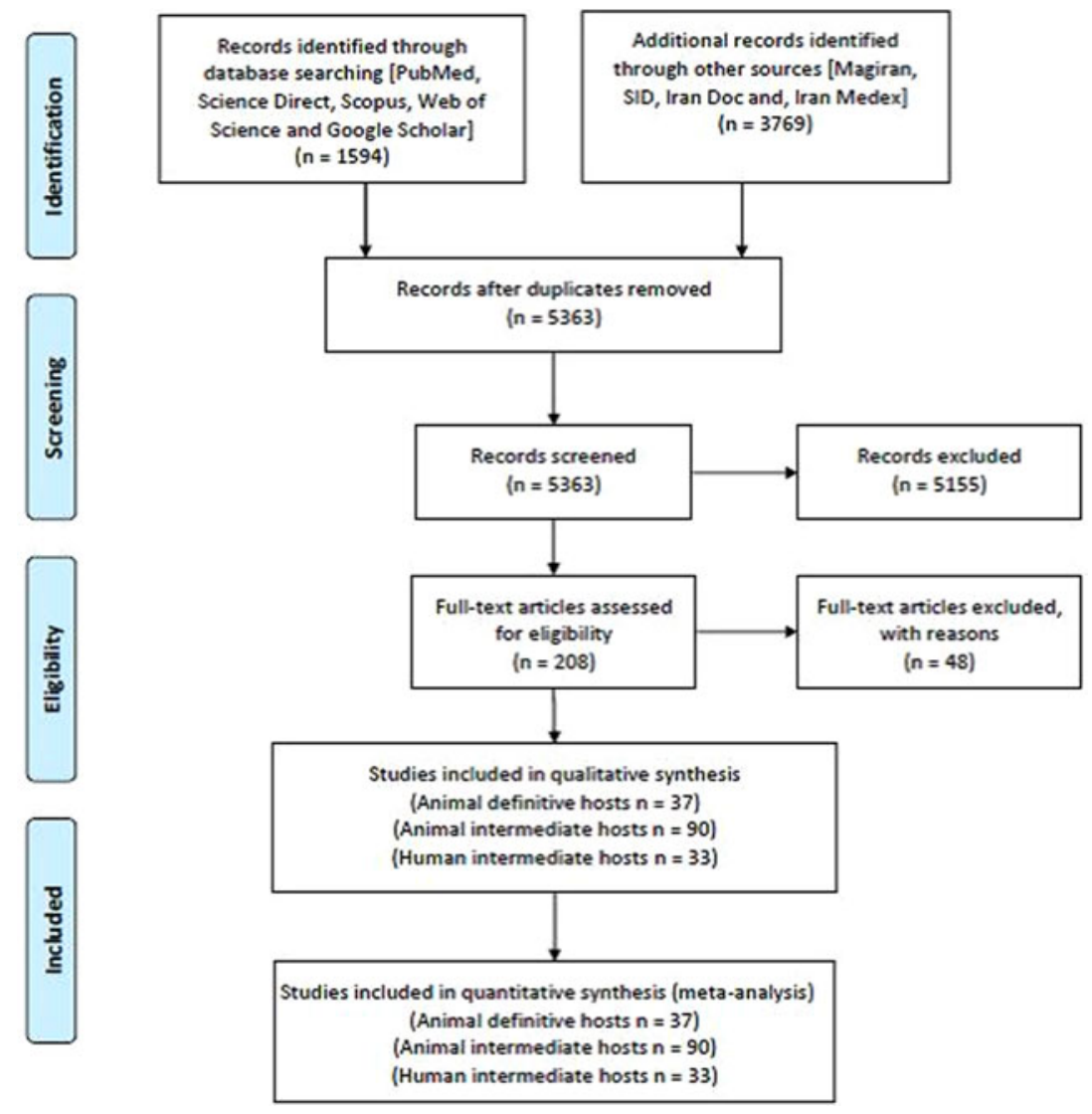

Fig. 1. Flowchart describing the study design process. 
Table 1. Results of included studies for definitive hosts.

\begin{tabular}{lccrr}
\hline Host & No. of studies & No. of individuals $(n)$ & No. of positive animals $(n)$ & Prevalence $(95 \%$ CI) \\
\hline Dogs & 31 & 10,696 & 1179 & $8.8 \%(8.1-11.9)$ \\
Fox & 9 & 399 & 118 & $14.9 \%(0.2-41.5)$ \\
Jackal & 8 & 259 & 37 & $10.6 \%(0.6-30.2)$ \\
Wolf & 3 & 12 & 5 & $39.0 \%(4.8-79.0)$ \\
\hline
\end{tabular}

Table 2. Geographical distribution and prevalence of included studies for definitive hosts.

\begin{tabular}{|c|c|c|c|c|c|c|c|}
\hline \multirow[b]{2}{*}{ Region } & \multirow[b]{2}{*}{ No. of studies } & \multirow[b]{2}{*}{ Prevalence $(95 \%$ CI) } & \multirow[b]{2}{*}{$I^{2} \%$} & \multicolumn{2}{|c|}{ Heterogeneity test } & \multicolumn{2}{|c|}{ Egger test } \\
\hline & & & & $Q$ & $P$ & $t$ & $P$ \\
\hline North & 5 & $25.2 \%(11.6-41.8)$ & 93.29 & 59.61 & $<0.001$ & 1.66 & 0.856 \\
\hline South & 1 & $36.2 \%(27.0-46.1)$ & & & & & \\
\hline Centre & 7 & $34.5 \%(24.3-45.6)$ & 90.82 & 65.37 & $<0.001$ & 2.04 & 0.278 \\
\hline West & 16 & $21.9 \%(10.9-35.5)$ & 98.09 & 786.45 & $<0.001$ & -0.35 & 0.731 \\
\hline East & 8 & $15.3 \%(8.0-24.1)$ & 93.81 & 113.01 & $<0.001$ & 1.24 & 0.039 \\
\hline Overall & 37 & $23.6 \%(17.6-30.1)$ & 97.64 & 1524.69 & $<0.001$ & 1.03 & 0.310 \\
\hline \multicolumn{4}{|c|}{ Test for heterogeneity between sub-groups: } & 31.76 & $<0.001$ & & \\
\hline
\end{tabular}

\section{Human intermediate hosts}

In this section, 33 studies were included (fig. 1 and supplementary table S3). Requisite data were extracted and studies were evaluated in terms of residence and gender risk factors (table 5). More people were infected in rural territories, with a prevalence of $4.1 \%(95 \% \mathrm{CI}=1.6-7.8 \%)$, than in urban areas. Additionally, mostly females were affected with CE, 4.5\% (95\% CI = 2.9-6.5\%). However, prevalence was not significantly associated with residence or gender $(P=0.172 ; P=0.718)$ (table 5 and supplementary tables $\mathrm{S} 4$ and S5).

The overall prevalence of cystic echinococcosis in human hosts of Iran was calculated as $4.2 \%(95 \% \mathrm{CI}=3.0-5.5 \%)$. Geographically, the highest prevalence was found in the south, with $5.8 \%$ (95\% CI=3.2-9.2\%), while the lowest prevalence was appointed to the central regions of the

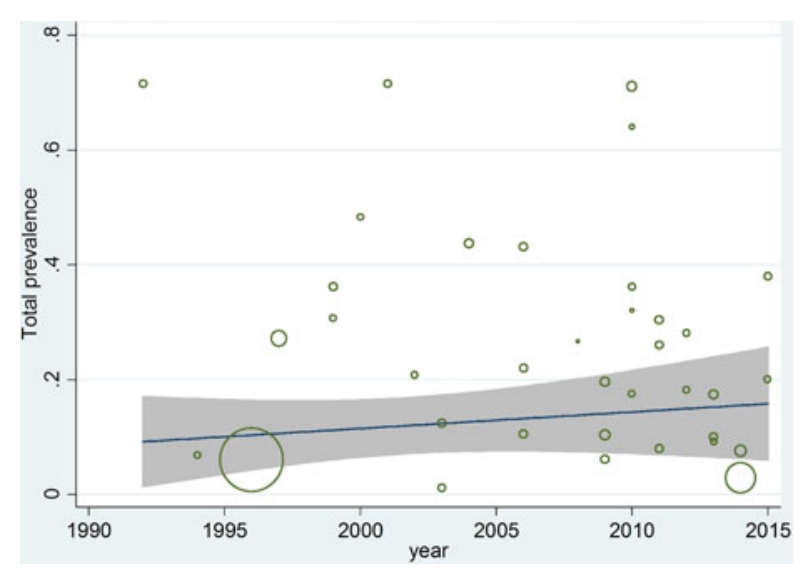

Fig. 2. Meta-regression plot of prevalence of Echinococcus granulosus in definitive hosts, based on year of studies. country, with $2.2 \%(95 \% \mathrm{CI}=1.3-3.4 \%)$ (table 6). Based on Egger's regression, publication bias did not have a considerable effect on total prevalence in human hosts $(P=0.4)$ (table 6).

Meta-regression between prevalence and both sample size and year of studies showed no significant correlation $(P=0.424 ; P=0.994)$ (figs 6 and 7$)$.

\section{Discussion}

This meta-analysis deals with the prevalence of CE in animal and human populations of Iran. With a synanthropic life cycle among dogs and domestic livestock, E. granulosus sensu lato infection has been distributed around the globe. Data from various provinces of Iran were acquired from online documented literature. Altogether, we searched

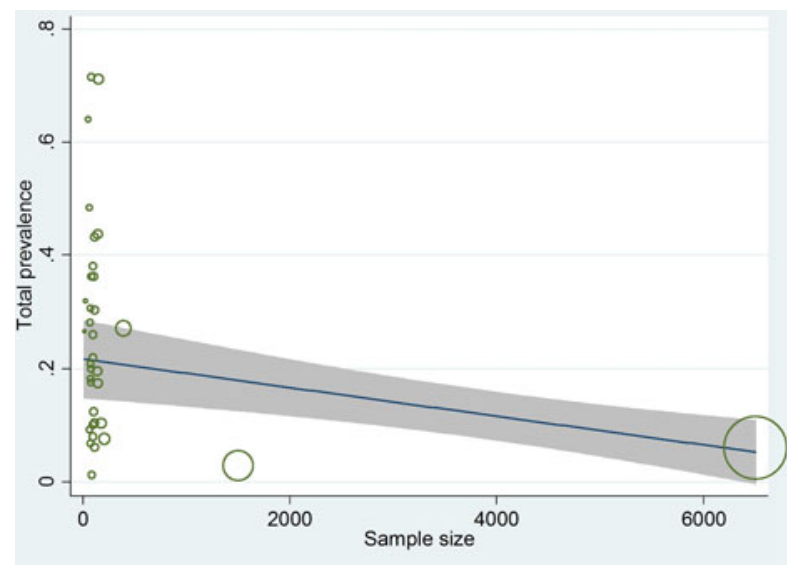

Fig. 3. Meta-regression plot of prevalence of Echinococcus granulosus in definitive hosts, based on sample size. 
Table 3. Results of included studies for animal intermediate hosts.

\begin{tabular}{lcccr}
\hline Host & No. of studies & No. of individuals $(n)$ & No. of positive animals $(n)$ & Prevalence $(95 \%$ CI) \\
\hline Cattle & 55 & $2,869,718$ & 260,592 & $8.8 \%(8.1-9.7)$ \\
Sheep & 60 & $14,466,454$ & 792,307 & $5.9 \%(4.9-7.1)$ \\
Goat & 50 & $3,404,007$ & 195,033 & $6.4 \%(5.6-7.7)$ \\
Buffalo & 16 & 91,811 & 16,953 & $16.5 \%(14.2-18.6)$ \\
Camel & 13 & 2938 & 920 & $32.7 \%(23.7-42.3)$ \\
Donkey/boar & 3 & 132 & 9 & $6.8 \%(0.6-17.5)$ \\
\hline
\end{tabular}

Table 4. Geographical distribution and prevalence of included studies for animal intermediate hosts.

\begin{tabular}{|c|c|c|c|c|c|c|c|}
\hline \multirow[b]{2}{*}{ Region } & \multirow[b]{2}{*}{ No. of studies } & \multirow[b]{2}{*}{ Prevalence $(95 \% \mathrm{CI})$} & \multirow[b]{2}{*}{$I^{2} \%$} & \multicolumn{2}{|c|}{ Heterogeneity test } & \multicolumn{2}{|c|}{ Egger test } \\
\hline & & & & $Q$ & $P$ & $t$ & $P$ \\
\hline North & 11 & $20.2 \%(13.7-27.7)$ & 99.99 & 327151.65 & $<0.001$ & 7.51 & 0.664 \\
\hline South & 8 & $18.1 \%(12.6-24.3)$ & 99.97 & 25566.43 & $<0.001$ & 7.77 & 0.281 \\
\hline Centre & 15 & $11.0 \%(7.4-15.0)$ & 99.96 & 36315.12 & $<0.001$ & 1.94 & 0.628 \\
\hline West & 42 & $16.8 \%(14.8-18.8)$ & 99.97 & 120877.5 & $<0.001$ & 13.16 & $<0.001$ \\
\hline East & 14 & $13.2 \%(10.1-16.8)$ & 99.55 & 126053.53 & $<0.001$ & 2.54 & 0.091 \\
\hline Overall & 90 & $15.6 \%(14.2-17.1)$ & 99.98 & 597601.37 & $<0.001$ & 5.03 & $<0.001$ \\
\hline \multicolumn{4}{|c|}{ Test for heterogeneity between sub-groups: } & 10.775 & 0.029 & & \\
\hline
\end{tabular}

nine databases for related articles. In the case of carnivore definitive hosts of $\mathrm{CE}, 37$ papers were found for $\mathrm{CE}$. The estimated total prevalence of infection in definitive hosts was calculated as $23.6 \%(95 \% \mathrm{CI}=17.6-30.1 \%)$. The goldstandard experiment for detecting infection in canine species is post-mortem examination (intestinal scraping) or sedimentation, while copro-antigen enzyme-linked immunosorbent assay (ELISA) is the method of choice in mass-screening studies (Deplazes et al., 1992; Eckert, 2003; Duscher et al., 2005; Barnes et al., 2012). There have been many studies on the prevalence of canine CE globally. In Africa, very high rates of infection have been detected, particularly in the northern and eastern regions, ranging from $3 \%$ in Tunisia to $66 \%$ in Uganda (Lahmar et al., 2008; Inangolet et al., 2010). Also, countries neighbouring Iran show a relatively heavy worm burden in dogs, with $49.5 \%$

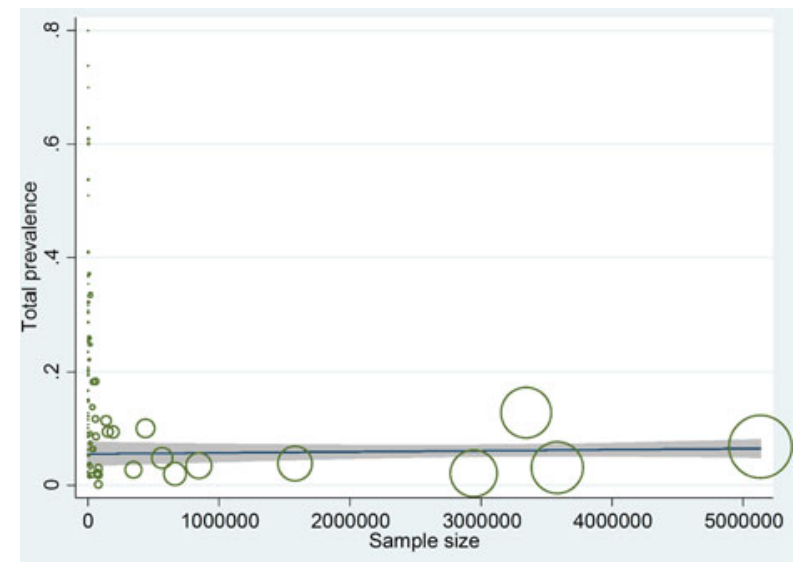

Fig. 4. Meta-regression plot of prevalence of Echinococcus granulosus in animal intermediate hosts, based on sample size. in Iraq (Saeed et al., 2000), 29.5\% in Jordan (Al-Qaoud et al., 2003), 28.2\% in Kazakhstan (Stefanic et al., 2004), $20.1 \%$ in Uzbekistan (Torgerson et al., 2006), 19\% in Kyrgyzstan (Ziadinov et al., 2008) and 15.2\% in Tajikistan (Torgerson et al., 2006). The range limits of rates of infection in Europe and the Americas are between 0.2-77.1\% and 1.8$79.2 \%$, respectively, and may reach rates greater than even $100 \%$ in Australia (Carmena \& Cardona, 2013). Three groups of risk factors contribute to disease dispersion in dogs, including biological (age of dog, worm burden and immunity), environmental (climate variations) and human behavioural elements (dog management and principles of slaughtering). Two outcomes are expected from appraising the prevalence and mean abundance of CE infection in carnivorous hosts: (1) to carefully monitor the control programmes; and (2) to evaluate the propagation, dynamics

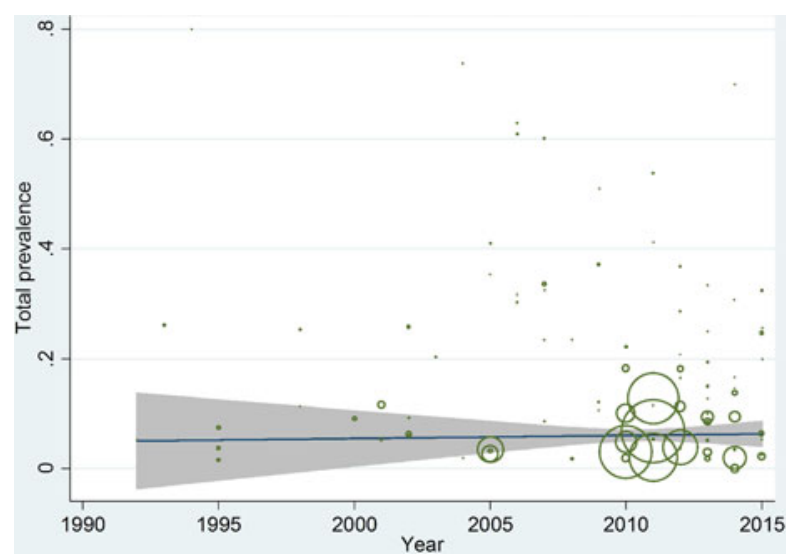

Fig. 5. Meta-regression plot of prevalence of Echinococcus granulosus in animal intermediate hosts, based on year of studies. 
Table 5. Results of included studies for human hosts.

\begin{tabular}{|c|c|c|c|c|c|c|}
\hline Risk factors & No. of studies & Category & Total individuals & Positive cases & Overall prevalence (\%) & $P$ value \\
\hline \multirow[t]{2}{*}{ Residence } & \multirow[t]{2}{*}{9} & Urban & 6774 & 133 & $2.1 \%(1.1-3.4)$ & \multirow[t]{2}{*}{0.172} \\
\hline & & Rural & 5464 & 191 & $4.1 \%(1.6-7.8)$ & \\
\hline \multirow[t]{2}{*}{ Gender } & \multirow[t]{2}{*}{20} & Male & 11,680 & 643 & $4.0 \%(2.4-6.0)$ & \multirow[t]{2}{*}{0.718} \\
\hline & & Female & 16,284 & 1032 & $4.5 \%(2.9-6.5)$ & \\
\hline
\end{tabular}

Table 6. Geographical distribution and prevalence of included studies for human hosts.

\begin{tabular}{|c|c|c|c|c|c|c|c|}
\hline \multirow[b]{2}{*}{ Region } & \multirow[b]{2}{*}{ No. of studies } & \multirow[b]{2}{*}{ Prevalence $(95 \%$ CI) } & \multirow[b]{2}{*}{$I^{2} \%$} & \multicolumn{2}{|c|}{ Heterogeneity test } & \multicolumn{2}{|c|}{ Egger test } \\
\hline & & & & $Q$ & $P$ & $t$ & $P$ \\
\hline North & 9 & $4.4 \%(2.3-7.0)$ & 96.24 & 212.62 & $<0.001$ & -1.04 & 0.46 \\
\hline South & 4 & $5.8 \%(3.2-9.2)$ & 90.04 & 30.13 & $<0.001$ & -0.91 & 0.69 \\
\hline Centre & 8 & $2.2 \%(1.3-3.4)$ & 90.09 & 70.67 & $<0.001$ & -0.27 & 0.69 \\
\hline West & 12 & $5.0 \%(2.7-8.1)$ & 98.49 & 727.79 & $<0.001$ & -0.30 & 0.86 \\
\hline Overall & 33 & $4.2 \%(3.0-5.5)$ & 97.24 & 1160.19 & $<0.001$ & -0.45 & 0.41 \\
\hline \multicolumn{4}{|c|}{ Test for heterogeneity between sub-groups: } & 9.145 & 0.027 & & \\
\hline
\end{tabular}

of transmission and status of human infection in a particular region (Craig et al., 2003; Romig et al., 2011; Barnes et al., 2012).

Among 90 records obtained from the literature review, weighted prevalence was evaluated as $15.6 \% \quad(95 \%$ $\mathrm{CI}=14.2-17.1 \%$ ) in animal intermediate hosts. Infection identification was similar to that of definitive hosts, relying mostly upon animal post-mortem inspection in abattoirs (Carmena \& Cardona, 2013). According to scientific reports in Africa, highest prevalences of hydatidosis in sheep $(0.2-68 \%)$, goats $(0.2-65 \%)$ and camels $(1.9-61 \%)$, were recorded (Bardonnet et al., 2002; Njoroge et al., 2002; Sissay et al., 2008). In Asia, the greatest rate of infection among production animals was found in sheep intermediate hosts (0.1-82.6\%) (Yu et al., 2008; Pednekar et al., 2009); furthermore, among Iran's neighbours, CE prevalence in sheep ranged from $7.5 \%$ in Pakistan (Latif et al.,

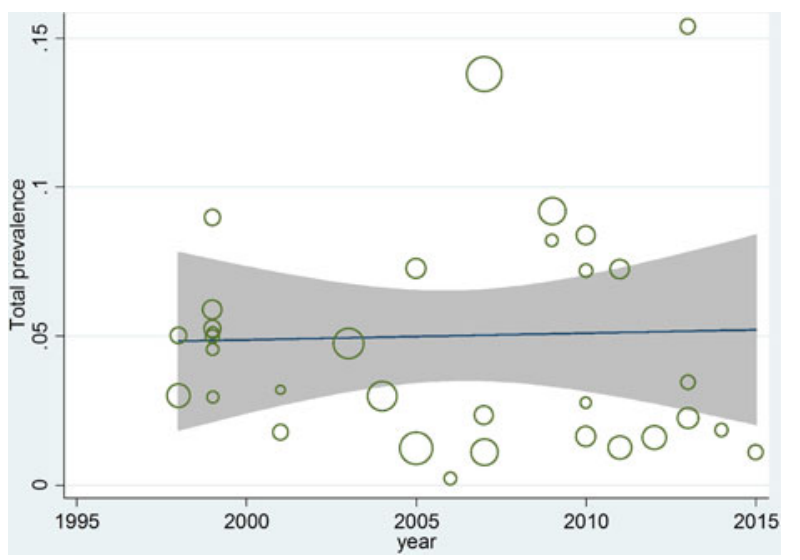

Fig. 6. Meta-regression plot of prevalence of Echinococcus granulosus in human hosts, based on year of studies.
2010) to $64.2 \%$ in Kyrgyzstan (Torgerson et al., 2009), while cattle and goat infections were 1.8-45.5.\% and 5.5-11.1\%, respectively (Torgerson et al., 2006; Latif et al., 2010; Guo et al., 2011). In Europe, sheep (0-75\%), and to a lesser extent cattle (0-41.5\%) and goats (0-25.7\%), were more involved and are considered to be the main intermediate hosts (Varcasia et al., 2006, 2007; European Food Safety Authority, 2015). The same situation exists in the Americas (Cardona \& Carmena, 2013; Carmena \& Cardona, 2013). Many risk factors may be involved in disease spatial distribution, such as farm hygiene practices and breeding conditions, environmental elements and strain/genotype of hydatid cysts, as well as sociocultural beliefs (Eckert \& Deplazes, 2004). Hydatid infection in livestock not only leads to the need to regulate disposal of infected viscera and dead animals, and to international restrictions on export of infected products,

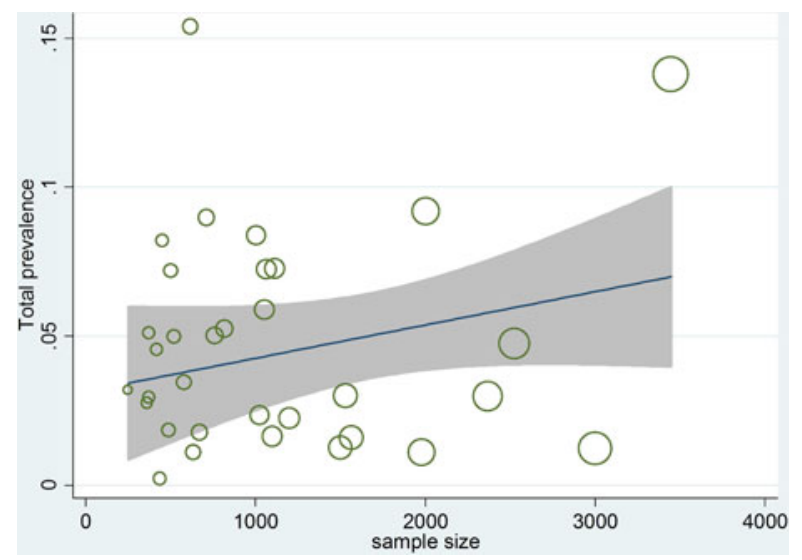

Fig. 7. Meta-regression plot of prevalence of Echinococcus granulosus in human hosts, based on sample size. 
but the infection also detracts from the quality and quantity of livestock products (milk, meat, wool and feathers) and reduces birth rates. Hence, requisite control measures should be taken into account (Torgerson, 2003).

In total, 33 articles related to humans as the aberrant intermediate hosts of hydatidosis were gathered, resulting in a $4.2 \%(95 \% \mathrm{CI}=3.0-5.5 \%)$ pooled prevalence of hydatid cyst infection. The infection rate was higher in rural regions, with $4.1 \%(95 \% \mathrm{CI}=1.6-7.8 \%)$; we also found that $4.5 \%$ (95\% CI $=2.9-6.5 \%)$ of women were infected, having more positive cases than men. The greatest rate of prevalence is frequently correlated with temperate regions. Human hydatidosis is an endemic infection in some parts of the world, including in Asia, Australia, South America, North Africa and the Mediterranean littoral (Kilic et al., 2003; Moro \& Schantz, 2006b, 2009; Yang et al., 2006). In these regions, the incidence rate of human CE was reported to be fewer than 50 cases/100,000 inhabitants (Mandal \& Mandal, 2012). Accordingly, in a recent systematic review (Budke et al., 2013), annual rates of incidence were limited to 0-32 cases $/ 100,000$ individuals in hospital-based studies, representing an optimistic hospitalization estimation of 32 cases every year. Besides, the prevalence of hydatid infection reached $1-7 \%$ in cross-sectional community-based studies. Consistent with our result, women showed elevated CE prevalence rates (prevalence proportion ratio: 1.35 ) in this review and hence are considered more prone to infection than men, probably due to traditional household tasks in endemic lands, such as dealing with dogs, gardening and food preparation. Based on Budke et al. (2013), with regard to imaging techniques, the three top prevalence rates of hepatopulmonary CE were assigned to China.

Our findings about the prevalence of cystic echinococcosis in Iran were affected by some limitations, comprising: (1) lack of a modulus question form to obtain needed information in most human studies; (2) lack of an appropriate, identical-examination method with high specificity and sensitivity; and (3) absence of studies in some regions of the country. These restrictions may bias the reported epidemiologic aspects of CE infection.

In Iran, it has been estimated that a financial burden of up to US\$232.3 million per annum is inflicted by CE, divided into human and animal cases with losses of US\$93.39 million and US\$132 million, respectively. Also, the surgical cost of human cases was estimated at US\$1539 (Fasihi Harandi et al., 2012). Disease control, reduction of infection prevalence in animals, and hence interrupting the transmission cycle, are not only decisive practices to lower the incidence rate of human hydatidosis, but also lead to an economically improved society. Therefore, given the information extracted from the current systematic review and meta-analysis, safety precautions and management programmes in cases of animal and human cystic echinococcosis should be devised.

\section{Supplementary material}

To view supplementary material for this article, please visit https://doi.org/10.1017/S0022149X17000463

\section{Acknowledgements}

The authors would like to thank all staff of the Department of Medical Parasitology and Mycology of Urmia University of Medical Sciences, Urmia, Iran.

\section{Authors' contributions}

S.K. conceived the study; S.K. and H.K. designed the study protocol; M.F. and S.K. searched the literature; P.K. and S.A. extracted the data; H.K. analysed and interpreted the data; H.M. wrote the manuscript; S.K., H.M. and A.A. critically revised the manuscript. All authors read and approved the final manuscript.

\section{Financial support}

This study received financial support from the Student Research Committee of Urmia University of Medical Sciences, Urmia, Iran (grant no: 1394-01-42-2157).

\section{Conflict of interest}

The authors declared no potential conflicts of interest with respect to the research, authorship and/or publication of this article.

\section{Ethical standards}

This study was approved by the Ethical Committee of Urmia University of Medical Sciences, Urmia, Iran (no.: Ir.UMSU.rec.1395.242).

\section{References}

Al-Qaoud, K.M., Abdel-Hafez, S.K. \& Craig, P.S. (2003) Canine echinococcosis in northern Jordan: increased prevalence and dominance of sheep/dog strain. Parasitology Research 90, 187-191.

Bardonnet, K., Piarroux, R., Dia, L., Schneegans, F., Beurdeley, A., Godot, V. \& Vuitton, D.A. (2002) Combined eco-epidemiological and molecular biology approaches to assess Echinococcus granulosus transmission to humans in Mauritania: occurrence of the 'camel' strain and human cystic echinococcosis. Transactions of the Royal Society of Tropical Medicine and Hygiene 96, 383-386.

Barnes, T.S., Deplazes, P., Gottstein, B., Jenkins, D.J., Mathis, A., Siles-Lucas, M., Torgerson, P.R., Ziadinov, I. \& Heath, D.D. (2012) Challenges for diagnosis and control of cystic hydatid disease. Acta Tropica 123, 1-7.

Budke, C.M., Carabin, H., Ndimubanzi, P.C., Nguyen, H., Rainwater, E., Dickey, M., Bhattarai, R., Zeziulin, O. \& Qian, M.B. (2013) A systematic review of the literature on cystic echinococcosis frequency worldwide and its associated clinical manifestations. American Journal of Tropical Medicine and Hygiene 88, 1011-1027.

Cardona, G.A. \& Carmena, D. (2013) A review of the global prevalence, molecular epidemiology and 
economics of cystic echinococcosis in production animals. Veterinary Parasitology 192, 10-32.

Carmena, D. \& Cardona, G.A. (2013) Canine echinococcosis: global epidemiology and genotypic diversity. Acta Tropica 128, 441-460.

Carmena, D. \& Cardona, G.A. (2014) Echinococcosis in wild carnivorous species: epidemiology, genotypic diversity, and implications for veterinary public health. Veterinary Parasitology 202, 69-94.

Craig, P.S., Rogan, M.T. \& Campos-Ponce, M. (2003) Echinococcosis: disease, detection and transmission. Parasitology 127 (Suppl.), S5-20.

Dakkak, A. (2010) Echinococcosis/hydatidosis: a severe threat in Mediterranean countries. Veterinary Parasitology 174, 2-11.

Deplazes, P., Gottstein, B., Eckert, J., Jenkins, D.J., Ewald, D. \& Jimenez-Palacios, S. (1992) Detection of Echinococcus coproantigens by enzyme-linked immunosorbent assay in dogs, dingoes and foxes. Parasitology Research 78, 303-308.

Duscher, G., Prosl, H. \& Joachim, A. (2005) Scraping or shaking - a comparison of methods for the quantitative determination of Echinococcus multilocularis in fox intestines. Parasitology Research 95, 40-42.

Eckert, J. (2003) Predictive values and quality control of techniques for the diagnosis of Echinococcus multilocularis in definitive hosts. Acta Tropica 85, 157-163.

Eckert, J. \& Deplazes, P. (2004) Biological, epidemiological, and clinical aspects of echinococcosis, a zoonosis of increasing concern. Clinical Microbiology Reviews 17, 107-135.

European Food Safety Authority (2015) The European Union summary report on trends and sources of zoonoses, zoonotic agents and food-borne outbreaks in 2013. EFSa Journal 13, 3991 pp.

Fasihi Harandi, M., Budke, C.M. \& Rostami, S. (2012) The monetary burden of cystic echinococcosis in Iran. PLoS Neglected Tropical Diseases 6, e1915.

Foroutan, M., Khademvatan, S., Majidiani, H., Khalkhali, H., Hedayati-Rad, F., Khashaveh, S. \& Mohammadzadeh, H. (2017) Prevalence of Leishmania species in rodents: a systematic review and meta-analysis in Iran. Acta Tropica 172, 164-172.

Foroutan-Rad, M., Khademvatan, S., Majidiani, H., Aryamand, S., Rahim, F. \& Malehi, A.S. (2016a) Seroprevalence of Toxoplasma gondii in the Iranian pregnant women: a systematic review and meta-analysis. Acta Tropica 158, 160-169.

Foroutan-Rad, M., Majidiani, H., Dalvand, S., Daryani, A., Kooti, W., Saki, J., Hedayati-Rad, F. \& Ahmadpour, E. (2016b) Toxoplasmosis in blood donors: a systematic review and meta-analysis. Transfusion Medicine Reviews 30, 116-122.

Guo, Z.H., Kubo, M., Kudo, M., Nibe, K., Horii, Y. \& Nonaka, N. (2011) Growth and genotypes of Echinococcus granulosus found in cattle imported from Australia and fattened in Japan. Parasitology International 60, 498-502.

Inangolet, F.O., Biffa, D., Opuda-Asibo, J., Oloya, J. \& Skjerve, E. (2010) Distribution and intensity of Echinococcus granulosus infections in dogs in Moroto District, Uganda. Tropical Animal Health and Production 42, 1451-1457.
Jenkins, D.J. (2006) Echinococcus granulosus in Australia, widespread and doing well! Parasitology International 55 (Suppl.), S203-206.

Jenkins, D.J., Romig, T. \& Thompson, R.C. (2005) Emergence/re-emergence of Echinococcus spp. - a global update. International Journal for Parasitology 35, 1205-1219.

Khademvatan, S., Yousefi, E., Rafiei, A., Rahdar, M. \& Saki, J. (2013) Molecular characterization of livestock and human isolates of Echinococcus granulosus from south-west Iran. Journal of Helminthology 87, 240-244.

Khademvatan, S., Foroutan, M., Hazrati-Tappeh, K., Dalvand, S., Khalkhali, H., Masoumifard, S. \& Hedayati-Rad, F. (2017) Toxoplasmosis in rodents: a systematic review and meta-analysis in Iran. Journal of Infection and Public Health. doi: 10.1016/j.jiph.2017.01.021.

Kilic, D., Cangir, A.K., Bulut, S. \& Akay, H. (2003) Hydatid cyst of the rib with intramedullary involvement. Acta Chirurgica Belgica 103, 334-335.

Lahmar, S., Sarciron, M.E., Rouiss, M. \& Mensi, M. (2008) Echinococcus granulosus and other intestinal helminths in semi-stray dogs in Tunisia: infection and re-infection rates. La Tunisie Medicale 86, 657-664.

Latif, A.A., Tanveer, A., Maqbool, A., Siddiqi, N., Kyaw-Tanner, M. \& Traub, R.J. (2010) Morphological and molecular characterisation of Echinococcus granulosus in livestock and humans in Punjab, Pakistan. Veterinary Parasitology 170, 44-49.

Magambo, J., Njoroge, E. \& Zeyhle, E. (2006) Epidemiology and control of echinococcosis in sub-Saharan Africa. Parasitology International 55 (Suppl.), S193-195.

Mandal, S. \& Mandal, M.D. (2012) Human cystic echinococcosis: epidemiologic, zoonotic, clinical, diagnostic and therapeutic aspects. Asian Pacific Journal of Tropical Medicine 5, 253-260.

McManus, D.P. (2010) Echinococcosis with particular reference to Southeast Asia. Advances in Parasitology 72, 267-303.

McManus, D.P., Zhang, W., Li, J. \& Bartley, P.B. (2003) Echinococcosis. Lancet, 362, 1295-1304.

Moher, D., Liberati, A., Tetzlaff, J., Altman, D.G. \& Group, P. (2010) Preferred reporting items for systematic reviews and meta-analyses: the PRISMA statement. International Journal of Surgery 8, 336-341.

Moro, P. \& Schantz, P.M. (2006a) Cystic echinococcosis in the Americas. Parasitology International 55 (Suppl.), S181-186.

Moro, P.L. \& Schantz, P.M. (2006b) Echinococcosis: historical landmarks and progress in research and control. Annals of Tropical Medicine and Parasitology 100, 703-714.

Moro, P. \& Schantz, P.M. (2009) Echinococcosis: a review. International Journal of Infectious Diseases 13, 125-133.

Njoroge, E.M., Mbithi, P.M., Gathuma, J.M., Wachira, T. M., Gathura, P.B., Magambo, J.K. \& Zeyhle, E. (2002) A study of cystic echinococcosis in slaughter animals in three selected areas of northern Turkana, Kenya. Veterinary Parasitology 104, 85-91.

Pawłowski, Z., Eckert, J., Vuitton, D., Ammann, R., Kern, P., Craig, P., Dar, K., Rosa, F.D., Filice, C. \& Gottstein, B. (2001) Echinococcosis in humans: clinical aspects, diagnosis and treatment. WHO/OIE manual on echinococcosis in humans and animals: a public health 
problem of global concern. pp. 20-66. Geneva, World Health Organization.

Pednekar, R.P., Gatne, M.L., Thompson, R.C. \& Traub, R.J. (2009) Molecular and morphological characterisation of Echinococcus from food producing animals in India. Veterinary Parasitology 165, 58-65.

Romig, T., Dinkel, A. \& Mackenstedt, U. (2006) The present situation of echinococcosis in Europe. Parasitology International 55 (Suppl.), S187-191.

Romig, T., Omer, R.A., Zeyhle, E., Huttner, M., Dinkel, A., Siefert, L., Elmahdi, I.E., Magambo, J., Ocaido, M., Menezes, C.N., Ahmed, M.E., Mbae, C., Grobusch, M.P. \& Kern, P. (2011) Echinococcosis in sub-Saharan Africa: emerging complexity. Veterinary Parasitology 181, 43-47.

Sadjjadi, S.M. (2006) Present situation of echinococcosis in the Middle East and Arabic North Africa. Parasitology International 55 (Suppl.), S197-202.

Saeed, I., Kapel, C., Saida, L.A., Willingham, L. \& Nansen, P. (2000) Epidemiology of Echinococcus granulosus in Arbil province, northern Iraq, 1990-1998. Journal of Helminthology 74, 83-88.

Sissay, M.M., Uggla, A. \& Waller, P.J. (2008) Prevalence and seasonal incidence of larval and adult cestode infections of sheep and goats in eastern Ethiopia. Tropical Animal Health and Production 40, 387-394.

Stefanic, S., Shaikenov, B.S., Deplazes, P., Dinkel, A., Torgerson, P.R. \& Mathis, A. (2004) Polymerase chain reaction for detection of patent infections of Echinococcus granulosus ('sheep strain') in naturally infected dogs. Parasitology Research 92, 347-351.

Torgerson, P.R. (2003) Economic effects of echinococcosis. Acta Tropica 85, 113-118.

Torgerson, P.R. \& Macpherson, C.N. (2011) The socioeconomic burden of parasitic zoonoses: global trends. Veterinary Parasitology 182, 79-95.

Torgerson, P.R., Oguljahan, B., Muminov, A.E., Karaeva, R.R., Kuttubaev, O.T., Aminjanov, M. \& Shaikenov,
B. (2006) Present situation of cystic echinococcosis in Central Asia. Parasitology International 55 (Suppl.), S207-212.

Torgerson, P.R., Ziadinov, I., Aknazarov, D., Nurgaziev, R. \& Deplazes, P. (2009) Modelling the age variation of larval protoscoleces of Echinococcus granulosus in sheep. International Journal for Parasitology 39, 1031-1035.

Varcasia, A., Canu, S., Lightowlers, M.W., Scala, A. \& Garippa, G. (2006) Molecular characterization of Echinococcus granulosus strains in Sardinia. Parasitology Research 98, 273-277.

Varcasia, A., Canu, S., Kogkos, A., Pipia, A.P., Scala, A., Garippa, G. \& Seimenis, A. (2007) Molecular characterization of Echinococcus granulosus in sheep and goats of Peloponnesus, Greece. Parasitology Research 101, 1135-1139.

Wang, Z., Wang, X. \& Liu, X. (2008) Echinococcosis in China, a review of the epidemiology of Echinococcus spp. Ecohealth, 5, 115-126.

Yang, Y.R., Sun, T., Li, Z. et al. (2006) Community surveys and risk factor analysis of human alveolar and cystic echinococcosis in Ningxia Hui Autonomous Region, China. Bulletin of the World Health Organization 84, 714-721.

Yu, S.H., Wang, H., Wu, X.H., Ma, X., Liu, P.Y., Liu, Y.F., Zhao, Y.M., Morishima, Y. \& Kawanaka, M. (2008) Cystic and alveolar echinococcosis: an epidemiological survey in a Tibetan population in southeast Qinghai, China. Japanese Journal of Infectious Diseases 61, 242-246.

Ziadinov, I., Mathis, A., Trachsel, D., Rysmukhambetova, A., Abdyjaparov, T.A., Kuttubaev, O.T., Deplazes, P. \& Torgerson, P.R. (2008) Canine echinococcosis in Kyrgyzstan: using prevalence data adjusted for measurement error to develop transmission dynamics models. International Journal for Parasitology 38, 1179-1190. 